\title{
Análise dos parâmetros clínicos e volumétricos das lesões de substância branca identificadas por ressonância magnética em mulheres portadoras de migrânea
}

\author{
Natália de Oliveira Silva ${ }^{\mathbb{D}}$, Júlio César Nather Júnior ${ }^{\circledR}$, Nicole Machado Maciel ${ }^{\circledR}$, Gabriela Ferreira Carvalho ${ }^{(\mathbb{D}}$, \\ Débora Bevilaqua-Grossi ${ }^{\mathrm{ID}}$, Fabíola Dach ${ }^{\mathrm{D}}$, Antônio Carlos dos Santos ${ }^{\mathrm{D}}$
}

Hospital das Clinicas da Faculdade de medicina de Ribeirão Preto, Universidade de São Paulo, Ribeirão Preto, São Paulo, Brasil.

\begin{abstract}
Introdução
As lesões de substância branca (LSB) são as alterações macroestruturais mais comuns na migrânea e estão relacionadas à perda mielínica/axonal, rarefação neuronal e gliose; porém seu significado clínico é incerto. A inflamação neurogênica, a depressão alastrante cortical e a oligoemia podem estar implicados na gênese dessas lesões. Assim, aventa-se o papel das LSBs como biomarcadores na migrânea.
\end{abstract}

\section{Objetivos}

Caracterizar as LSBs em mulheres com migrânea quanto à presença, número, volume e localização. Comparar as LSBs entre os grupos: migrânea sem aura, migrânea com aura, migrânea crônica e grupo controle. Avaliar a influência de variáveis clínicas sobre as características das LSBs.

\section{Material e Métodos}

Estudo transversal com 60 voluntárias, entre 18-55 anos, alocadas igualmente entre os grupos, pareadas por média de idade, submetidas à ressonância magnética de alta resolução. As imagens foram processadas por softwares de morfometria baseada em voxel. As lesões foram identificadas e segmentadas manualmente por um neurologista e avaliadas cegamente por 2 neurorradiologistas.

\section{Resultados}

Os testes de Mann-Whitney, Kruskal-Wallis e Coeficiente de Spearman foram utilizados para análise estatística. Não houve diferença nas variáveis de LSB entre os grupos, o que se manteve nas análises de subgrupo quando as lesões foram caracterizadas por tamanho e localização. A idade e o tempo de doença foram as variáveis clínicas que mais influenciaram as LSB, sobretudo na ínsula. A frequência de aura influenciou as LSBs do lobo temporal. Não foram encontradas correlações com frequência de crises, intensidade de dor e tratamento profilático. Todas as LSBs foram supratentoriais e predominaram nos territórios de circulação anterior.

\section{Conclusão}

O tipo de migrânea não influencia na formação de LSBs. A ínsula e o lobo temporal podem estar envolvidos na fisiopatologia da crise migranosa. Não foi possível estabelecer se a migrânea é um fator de risco para LSBs.

Palavras-chave: Migrânea, Lesão de substância branca, Ressonância Magnética, Volumetria, Morfometria baseada em voxel.

Este trabalho contou com o apoio financeiro da FAPESP. 